\title{
Cerebral Glucose Utilization in Polysubstance Abuse
}

June M. Stapleton, Ph.D., Michael J. Morgan, Ph.D., Robert L. Phillips, Ph.D., Dean F. Wong, M.D., Ph.D., Babington C.-K. Yung, M.D., Elias K. Shaya, M.D., Robert F. Dannals, Ph.D., Xiang Liu, M.D., Roger L. Grayson, M.D., and Edythe D. London, Ph.D.

Regional cerebral glucose metabolism in subjects with histories of polysubstance abuse was compared to that in control subjects who were drawn from the same community. The substance abuse group showed lower absolute metabolic rates for glucose in lateral occipital gyrus and higher normalized metabolic rates in temporal and frontal areas, including orbitofrontal cortex. It is suggested that some patterns of brain function associated with polysubstance abuse may represent consequences of drug exposure, or they could reflect pre-existing differences that may be relevant to the etiology and maintenance of polysubstance abuse.

[Neuropsychopharmacology 13:21-31, 1995]
KEY WORDS: Cerebral glucose metabolism; Brain imaging; Positron emission tomography; Substance abuse; Drug abuse; Fluorodeoxyglucose

Previous studies in our laboratory have demonstrated that cerebral glucose utilization is reduced after acute administration of morphine or cocaine in polysubstance abuse subjects (London et al. 1990a, b). As long-lasting cognitive impairments have been observed in substance abuse patients after detoxification, it was of interest to assess whether neuroanatomical patterns of functional brain activity, inferred from regional cerebral metabolic

From the Division of Intramural Research, National Institute on Drug Abuse, National Institutes of Health (JMS, MJM, RLP, BC-KY, XL, EDL); Departments of Radiology (DFW, EKS, RFD, EDL) and Anesthesiology (RLG), Johns Hopkins University School of Medicine; and Department of Pharmacology and Experimental Therapeutics, School of Medicine, University of Maryland, Baltimore, MD (EDL).

Address correspondence to: Edythe D. London, Ph.D., Chief, Neuroimaging and Drug Action Section, NIDA Addiction Research Center, P.O. Box 5180, Baltimore, MD 21224.

Received March 21, 1994; revised November 18, 1994; accepted December 12, 1994 rate(s) for glucose (rCMRglc), differ in detoxified substance abuse subjects compared to control subjects drawn from the same community.

The constellation of deficits in neuropsychological, electrophysiological, structural, and biochemical measures of brain function associated with substance abuse has been characterized more thoroughly for ethanol than for any other single drug or combination of drugs. Detoxified alcoholics show residual impairments in visuospatial processing, memory, and mental control functions, even in the absence of alcohol amnestic disorder or alcohol-related dementia (Eckardt and Ryback 1981; Parsons et al. 1987). They also show abnormalities in spontaneous electroencephalographic activity and event-related potentials as well as reductions in regional cerebral blood flow and rCMRglc (Berglund and Ingvar 1976; Martin et al. 1992; Porjesz and Begleiter 1983; Sachs et al. 1987; Volkow et al. 1992a).

Effects of other drugs on brain function are less well documented, but clear findings regarding some drugs have been reported (Miller 1985; Parsons and Farr 1981). Chronic use of inhalants, such as toluene, can produce long-lasting encephalopathy (Allison and Jerrom 1984; Knox and Nelson 1966; Mahmood 1983; Rosenberg et 
al. 1988). Cocaine has been reported to produce abnormalities in the brain, particularly related to the cerebral vasculature. The abnormalities include cerebral hemorrhage, migraine-like headache, and reduced cerebral blood flow (Lipton et al. 1989; Nalls et al. 1989; Rowbotham 1988; Satel and Gawin 1989; Spivey and Euerle 1990; Volkow et al. 1988). Chronic use of phencyclidine (PCP) has been associated with cognitive impairment, particularly in memory functions, and with reduced glucose utilization in frontal lobe compared to controls (Fauman and Fauman 1978; Lewis and Hordan 1986; Wu et al. 1991).

Polysubstance abuse is of particular interest since it has become a common pattern of drug abuse. Impairments in neuropsychological performance have been reported in several studies, and polysubstance abuse subjects have been reported to show ventricular dilatation on $x$-ray roentgenographic computerized tomography $(\mathrm{CT})$ and focal perfusion abnormalities on single photon emission computed tomography (Cascella et al. 1991; Grant and Mohns 1975; Grant et al. 1978; Holman et al. 1991; Meek et al. 1989; Schmitt et al. 1984). Assessment of neuroanatomical patterns of cerebral glucose metabolism may contribute to characterizing the alterations in brain function associated with polysubstance abuse.

\section{METHODS}

Subjects were right-handed, male volunteers, 23 to 43 years of age, recruited by newspaper advertisements. They showed no pathological conditions in a complete physical examination and in standard diagnostic tests, including complete blood cell count, serum electrolyte assay, liver function tests, fasting blood glucose level, prothrombin and partial thromboplastin times, thyroid function tests, urinalysis, electrocardiography, and tests for exposure to tuberculosis, viral hepatitis, and human immunodeficiency virus. The patency of radial and ulnar arteries in both arms was demonstrated by Allen's test.

Twenty polysubstance abuse subjects participated in a study of the acute effects of cocaine on rCMRglc, measured by using positron emission tomography (PET) with the [F-18]fluorodeoxyglucose (FDG) method (London et al. 1990b). Cerebral metabolic activity was measured in two sessions, one under the influence of cocaine and one with saline (placebo). While studies on the substance abuse subjects were ongoing, 10 normal control subjects were recruited specifically for the present study, and they participated in two PET sessions, both with placebo. Results from our laboratory suggest that when metabolic rate is measured with identical procedures on two separate occasions in the same subjects, there is a difference in metabolic rate between the first and second PET session (Stapleton et al. manuscript in preparation). For this reason, the present study utilized data from only those polysubstance abuse subjects $(n=10)$ who received placebo for their first PET session, and their data were compared to the data from the first PET session for the control subjects $(n=10)$.

Control subjects were recruited, by advertisement, from the same community as the substance abuse subjects. A subject was excluded from the control group if he reported any intravenous (IV) drug use. Past experimental use of drugs by other routes was permitted (fewer than 10 times in a lifetime), but no regular or current use, except for light use of alcohol and marijuana as well as unlimited tobacco smoking and unlimited consumption of beverages containing caffeine. To qualify for the cocaine study, the substance abuse subjects were required to have had prior experience with cocaine by the intravenous route. They also used tobacco, opioids, marijuana, amphetamine, and/or ethanol. Self-reports of current and past drug use were obtained from all subjects using a structured interview and the Addiction Severity Index (McLellan et al. 1980).

The National Institute of Mental Health Diagnostic Interview Schedule (DIS), modified for computerized self-administration, was used to detect psychiatric disorders (Robins et al. 1981). Criteria of the Diagnostic and Statistical Manual of Mental disorders (DSM III) (APA 1980) were applied. No Axis I diagnoses other than those related to substance abuse and/or dependence were found for subjects in the substance abuse group. No control subjects met criteria for any Axis I diagnosis other than nicotine dependence. Six substance abuse subjects met criteria for antisocial personality disorder, and one met criteria for pathological gambling. No other Axis II diagnoses were present in the substance abuse group, and none were found in the control group. A score of at least 18 on the Vocabulary subtest of the Shipley Institute of Living Scale was required (Zachary 1986). Subjects were excluded from further study if they showed any visible brain abnormality on a noncontrast CT or magnetic resonance imaging (MRI) scan of the brain. All subjects were paid for their participation and gave written informed consent under the supervision of the Institutional Review Boards of Johns Hopkins Hospital and Francis Scott Key Medical Center, Baltimore, MD, which houses the Addiction Research Center.

All subjects (Substance Abuse and Control) resided on a supervised residential unit during the study to ensure compliance with restrictions on self-administration of drugs outside the research protocol. Subjects were admitted at least 14 days before the first PET scan and remained until the morning after the second PET scan. Nicotine (cigarettes) and caffeine (beverages) were permitted ad libitum except on study days. Compliance was monitored by urine toxicology screening for opi- 
ates, cocaine, marijuana, and amphetamines. Testing was performed on admission and at random, unannounced time points during residence. Prior to the PET scan, each substance abuse subject participated in four preliminary sessions, two with placebo and two with cocaine (20 and $40 \mathrm{mg}$ IV). The last preliminary session (40 mg cocaine IV) occurred at least 24 hours and no more than 30 days before the PET scan. The last selfadministered cocaine exposure occurred 16 to 58 days before the PET scan. Control subjects participated in one preliminary session with placebo in order to become familiarized with the procedures. Spontaneous EEG was recorded during preliminary sessions.

Procedures for PET data collection have previously been described in detail (London et al. 1990b) and are briefly summarized here. Each subject was fitted with a molded plastic face mask to facilitate positioning in the PET scanner as well as for CT and/or MRI scanning. On the day of each PET scan, the subject was given a standard, nonketogenic, caffeine-free breakfast and then was deprived of food for at least 4 hours and of cigarettes for at least 2 hours before the injection of radiotracer. A radial arterial catheter was inserted after the administration of local anesthetic ( $0.5 \%$ lidocaine $\mathrm{HCl}$, subcutaneously). Intravenous catheters were placed in forearm veins of both arms. An intravenous infusion of $0.45 \% \mathrm{NaCl}$ was initiated in the arm opposite to the arterial catheter. From about 30 minutes before until 30 minutes after injection of the radiotracer, subjects were blindfolded and under headphones with white noise and a tone presented once per minute to prompt a self-report of subjective drug effect.

Subjects received an intravenous placebo injection simultaneously with the radiotracer injection. The substance abuse subjects did not know whether they would receive placebo or cocaine for their first session. Drug order was double-blind, randomized, and counterbalanced. Control subjects, however, knew that they would receive placebo for all sessions. Vital signs were monitored during all studies.

Subjects completed a set of questionnaires at about 60 minutes before, 30 minutes before, and 30 minutes after injection of the radiotracer. Questionnaires included a Visual Analog Scale for drug effects, the Cocaine Sensitive Scale (CSS), and three subscales from the Addiction Research Center Inventory (ARCI): the Morphine Benzedrine Group (MGB) subscale, a measure of positive subjective effects; the Pentobarbital Chlorpromazine Alcohol Group (PCAG) subscale, sensitive primarily to fatigue and sedation, and the LSD subscale, a measure of disorientation and weird feelings (Haertzen 1974; Muntaner et al. 1989). The CSS was also administered over the headphones at 1, 5, 15, and 20 minutes after the injection.

PET data were collected using the FDG procedure as previously described, including arterial blood sam- pling according to a fixed schedule (London et al. 1990b). Twelve images, on 8-mm centers parallel to the inferior orbitomeatal (IOM) plane, were obtained. Modeling of metabolic rates was performed using the operational equation of Huang et al. (1980). Data were quantified using a PET image analysis system (LOATS Associates Inc, Westminster, MD). All data were expressed as metabolic rates $(\mathrm{mg} / 100 \mathrm{~g}$ tissue/min). Figure 1 shows the location of the regions of interest (ROI), identified using an anatomical atlas (Hanaway et al. 1980). ROIs were located visually on PET images for each session, with viewing of the CT or MRI films to guide anatomical placement. Average rCMRglc for each slice was determined using an edge-finding algorithm. Global cerebral metabolic rate for glucose was estimated by computing the weighted average of the seven slices used for analysis of ROIs.

Statistical comparisons were performed with a criterion of $p<.05$ using Biomedical Data Program (BMDP) $4 \mathrm{v}$ for analysis of variance (ANOVA) with Greenhouse-Geisser correction as appropriate, and 8D for correlations (Dixon et al. 1988).

\section{RESULTS}

Characteristics of the subjects are shown in Table 1 . The two groups did not differ significantly in age, education, or full scale IQ on the Wechsler Adult Intelligence Scale-Revised. Most of the volunteers in both groups were African American. Self-reported drug use of the two groups is summarized in Tables 2 and 3 . As expected, the control group reported only light use of alcohol and marijuana as well as cigarette smoking, and the substance abuse group reported substantial recent and past use of a variety of drugs, including heroin and cocaine.

Each variable derived from subjective responses and measurement of vital signs was submitted to ANOVA with factors of Group (control or substance abuse) by Time $(-60,-30,+30 \mathrm{~min}$ from injection). No statistically significant main effects or interactions were found for the MBG, PCAG, or LSD subscales of the $\mathrm{ARCI}$ or for respiration, oral temperature, or heart rate.

Mean rCMRglc ( \pm SEM) for each ROI is shown in Table 4. Data for each brain structure were submitted to ANOVA with factors of Group (control or substance abuse) by Laterality (left or right), with the Laterality factor omitted for midline structures. The substance abuse group showed lower glucose utilization than the control group in lateral occipital gyrus. For both groups, rCMRglc was higher on the right than on the left for superior frontal gyrus, supramarginal gyrus, primary visual cortex, cuneus, putamen, and thalamus. It was higher on the left than on the right for superior tem- 


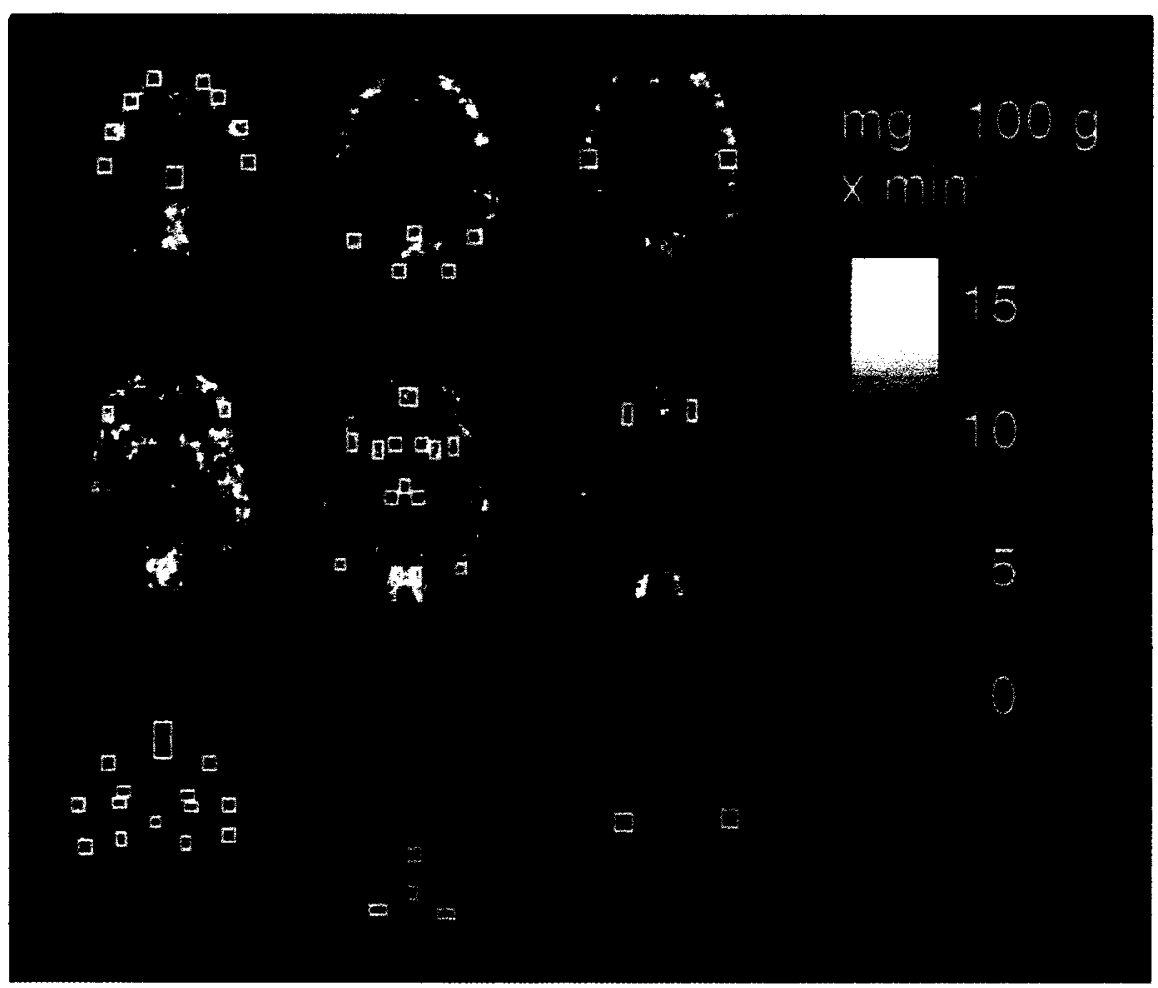

Figure 1. Template of ROIs for sampling rCMRglc. Placement of ROIs is indicated by white boxes on transforms of PET images, color-coded according to $\mathrm{rCMRglc}$ ( $\mathrm{mg} / 100 \mathrm{~g} / \mathrm{min}$ ). Regions measured include: (1) superior frontal gyrus (left and right), middle frontal gyrus (left and right), precentral gyrus (left and right), postcentral gyrus (left and right), paracentral lobule (midline); (2) superior parietal gyrus (left and right), cuneus (left and right), precuneus (midline); (3) supramarginal gyrus (left and right); (4) inferior frontal gyrus (left and right); (5) anterior cingulate gyrus (midline), insula (left and right), caudate nucleus (left and right), putamen (left and right), thalamus (left, right and midline), primary visual cortex (left and right), lateral occipital gyrus (left and right); (6) orbitofrontal cortex (left and right); (7) gyrus rectus (midline), superior temporal gyrus (left and right), middle temporal gyrus (left and right), inferior temporal gyrus (left and right), amygdala (left and right), hippocampus (left and right), parahippocampal gyrus (left and right), midbrain (midline); (8) pons (midline), cerebellum (left, right and midline); (9) temporal pole (left and right).

poral gyrus, amygdala, and hippocampus. For middle frontal gyrus and precentral gyrus, statistically significant interactions between Group and Laterality were found, but these interactions were in opposite directions. For middle frontal gyrus, rCMRglc on the right exceeded rCMRglc on the left more for the control group than for the substance abuse group. For precentral gyrus, rCMRglc on the right exceeded

Table 1. Characteristics of Research Subjects

\begin{tabular}{lcc}
\hline & Control & Substance Abuse \\
\hline Age (years) $^{a}$ & $29.7 \pm 1.2$ & $32.6 \pm 1.7$ \\
Education (years) $^{a}$ & $12.7 \pm 0.6$ & $12.5 \pm 0.4$ \\
Full Scale IQ $^{a}$ & $94.4 \pm 3.7$ & $97.8 \pm 4.4$ \\
Race & & \\
White & $2 / 10$ & $4 / 10$ \\
African American & $7 / 10$ & $6 / 10$ \\
Native American & $1 / 10$ & $0 / 10$ \\
\hline
\end{tabular}

${ }^{a}$ Each value is the mean \pm SEM for $n=10$ per group.
rCMRglc on the left more for the substance abuse group than the control group.

Visual inspection of color-coded brain images revealed that the control subjects showed a relatively uniform pattern of cerebral glucose metabolism compared to the substance abuse subjects, whose rCMRglc appeared to be reduced posteriorly (Figure 2 ). To derive a composite measure for each corticai iobe, a weighted average of all ROIs measured bilaterally in a given lobe was computed. The frontal and occipital composite measures were submitted to an ANOVA with factors of Group (control or substance abuse) by AnteriorPosterior (frontal or occipital) by Laterality (left or right). In addition to statistically significant Anterior-Posterior (frontal > occipital) and Laterality (right $>$ left) effects, this analysis yielded a statistically significant interaction of Group by Anterior-Posterior. This interaction reflected a larger difference between frontal and occipital composite measures of glucose metabolism for the substance abuse group (frontal: $9.54 \pm 0.18$, occipital: $8.70 \pm 0.21$ ) than for the control group (frontal: $9.56 \pm$ 0.21 , occipital: $9.43 \pm 0.23$ ).

Mean global metabolic rate ( $\mathrm{mg} / 100 \mathrm{~g}$ tissue $/ \mathrm{min}$.) 
Table 2. Incidence of Drug Use

\begin{tabular}{|c|c|c|c|c|}
\hline & \multicolumn{2}{|c|}{ Control $(n)$} & \multicolumn{2}{|c|}{ Substance Abuse $(n)$} \\
\hline & $\begin{array}{l}\text { Subjects Who } \\
\text { Ever Used }\end{array}$ & $\begin{array}{l}\text { Subjects Who } \\
\text { Recently Used }\end{array}$ & $\begin{array}{l}\text { Subjects Who } \\
\text { Ever Used }\end{array}$ & $\begin{array}{l}\text { Subjects Who } \\
\text { Recently Used }^{a}\end{array}$ \\
\hline Cigarettes & 6 & 6 & 10 & 10 \\
\hline Alcohol & 10 & 3 & 10 & 7 \\
\hline Heroin & 0 & 0 & 9 & 5 \\
\hline Other opiates & 1 & 0 & 6 & 0 \\
\hline Cocaine & 1 & 0 & 10 & 7 \\
\hline Marijuana & 6 & 2 & 10 & 7 \\
\hline Minor tranquilizers & 0 & 0 & 4 & 0 \\
\hline Amphetamine & 1 & 0 & 4 & 1 \\
\hline Barbiturates & 0 & 0 & 2 & 1 \\
\hline Hallucinogens & 0 & 0 & 5 & 1 \\
\hline Phencyclidine & 0 & 0 & 3 & 0 \\
\hline Inhalants & 0 & 0 & 1 & 0 \\
\hline
\end{tabular}

${ }^{a}$ Recently used $=$ within 2 weeks before the preadmission interview.

for the substance abuse group $(6.91 \pm 0.17)$ did not differ significantly from the rate for the control group $(7.27 \pm 0.21)$. Metabolic rate data for each region were submitted to Analysis of Covariance (ANCOVA) with the global metabolic rate as a covariate. Table 5 shows the resulting adjusted means. In these analyses the substance abuse group showed higher glucose utilization in superior frontal gyrus, middle temporal gyrus, insula, and orbitofrontal cortex than the control group. Main effects of laterality were found for the same structures as in the ANOVAs without covariate.

For the data from substance abuse subjects only, correlations were computed between rCMRglc for each $\mathrm{ROI}$ and five measures of cocaine use and withdrawal. Significant positive correlations were found between the number of days before the PET scan since the last exposure to cocaine ( $40 \mathrm{mg} I V$, given in the laboratory) and rCMRglc in primary visual cortex, left $[r(\mathrm{df} 8)=-$ $0.68, p=.03]$ and right $[r(\mathrm{df} 8)=0.65, p=.04]$. Significant positive correlations were found between the number of days since the last self-administration of cocaine (preadmission) and rCMRglc in left caudate nucleus $[r(\mathrm{df} 8)=0.66, p=.04]$ and left putamen $[r(\mathrm{df} 8)=0.77, p=.01]$. No significant correlations were found between rCMRglc in any region and the number of days of cocaine use in the last 14 days before the report (preadmission) or the average amount of selfreported preadmission cocaine use.

\section{DISCUSSION}

These data demonstrate that, compared to control subjects, polysubstance abuse subjects showed a steeper anterior-posterior gradient and lower absolute rCMRglc in the lateral occipital gyrus, with a tendency toward similar effects in other posterior areas, particularly in the occipital lobe. Studies on abusers of PCP, cocaine, and ethanol (with or without organic brain syndrome) have reported no significant differences from controls in rCMRglc of the occipital lobe (Martin et al. 1992; Sachs et al. 1987; Volkow et al. 1992a; Wu et al. 1991). This discrepancy could reflect differences in the populations studied. Our subjects differed from those of previous studies in several ways, including a required history of intravenous drug use and use of a wide range of drugs, including opioids. Alternatively, it could reflect

Table 3. Amount of Recent Drug Use ${ }^{a}$

\begin{tabular}{lcr}
\hline & Control & Substance Abuse \\
\hline Cigarettes (number of cigarettes) & $145.8 \pm 31.8(6)$ & $150.9 \pm 20.5(9)$ \\
Alcohol (number of drinks) & $7.0 \pm 1.5(3)$ & $38.4 \pm 13.0(7)$ \\
Marijuana (grams) & $4.5 \pm 2.5(2)$ & $21.7 \pm 7.2(7)$ \\
Heroin (grams) & 0 & $5.5 \pm 1.4(5)$ \\
Cocaine (grams) & 0 & $2.8 \pm 1.2(7)$ \\
\hline
\end{tabular}

\footnotetext{
${ }^{a}$ Mean \pm SEM. ( $n$ ). Data reflect self-reports of average drug use per week for the 2 weeks preceding the preadmission interview. Only data from subjects who indicated use of a specified drug recently (within 2 weeks) are included.
} 


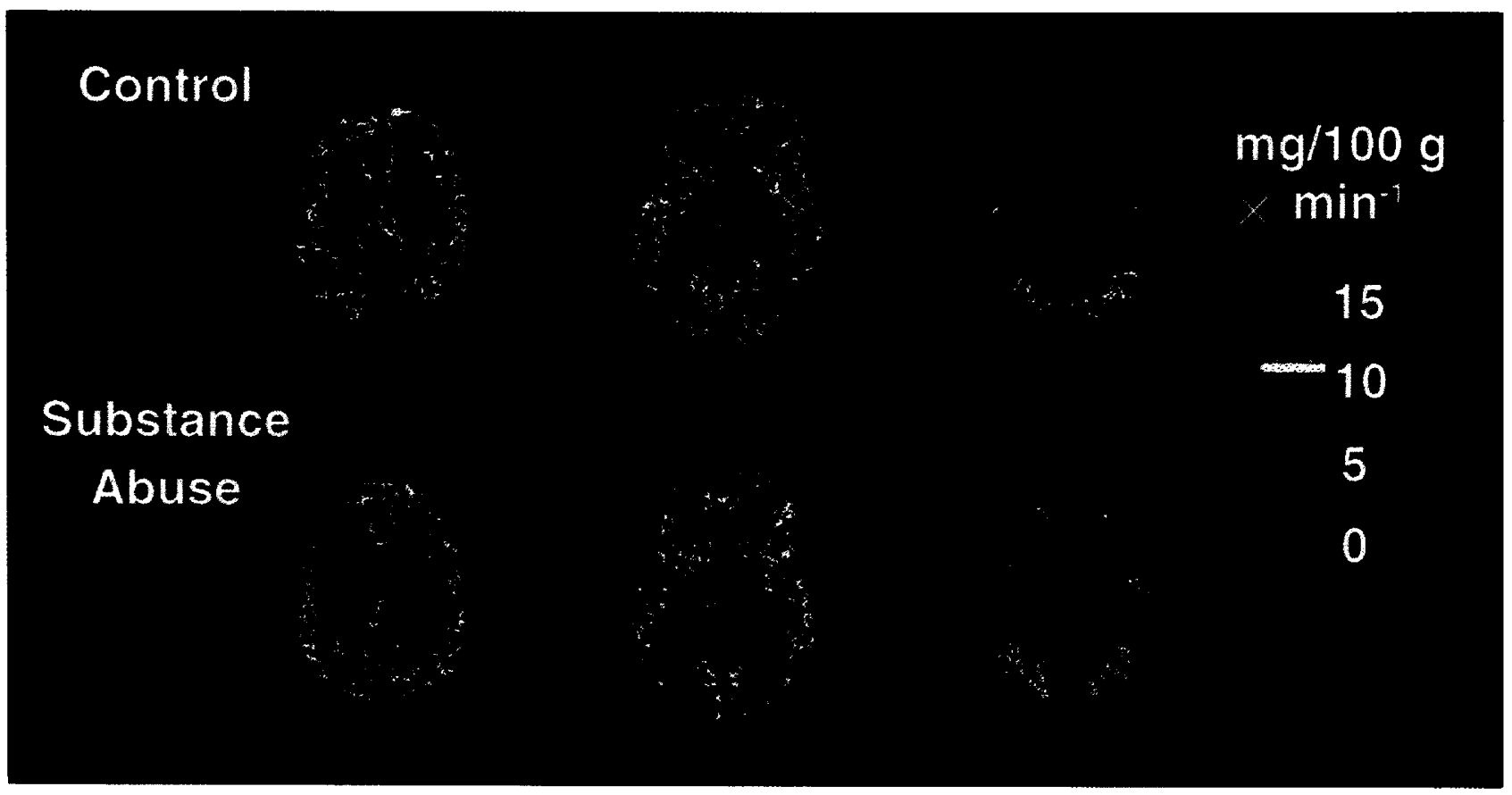

Figure 2. Color-coded transforms showing rCMRglc at three levels (80, 48, and $16 \mathrm{~mm}$ above IOM) in a typical subject from each of the two groups. Cerebral metabolism is more homogeneous in control subjects, whereas subjects in the substance abuse group appear to have lower rates of metabolism in posterior brain regions (primarily in occipital lobe).

procedural differences. All of the previously cited studies were conducted with the subjects having their eyes open, either resting or performing a visual task. In contrast, all subjects in the current study had eyes closed and covered. In normal subjects, increased visual stimulation leads to increased rCMRglc in visual areas (Kushner et al. 1988; Phelps et al. 1981). It is possible that rCMRglc in areas of visual cortex in substance abuse subjects does not differ from controls under conditions of low-level visual stimulation, but that the visual system is less spontaneously active in substance abusers in the absence of stimulation.

The present data cannot address the issue of whether the difference between substance abuse subjects and controls is a consequence of drug exposure or is a pre-existing difference. It is tempting to speculate that an abnormality in self-generated brain activity could be a predisposing factor related to the high levels of sensation-seeking thought to be characteristic of individuals that engage in substance abuse (Zuckerman 1986). It is also possible that cocaine withdrawal may contribute to the group differences. The four significant correlations reported between rCMRglc and measures of cocaine use and withdrawal are fewer than would be expected by chance. Nevertheless, the finding of significant correlations between rCMRglc in caudate and putamen and a measure of cocaine withdrawal is concordant with a previous report (Volkow et al. 1991) of correlation between number of days of withdrawal and rCMRglc in basal ganglia. On the other hand, we did not see a correlation between duration of abstinence and rCMRglc in orbitofrontal cortex as reported by Volkow et al. (1991). This discordance may be due to differences in placement of ROIs. It appears that our orbitofrontal measure was more lateral than that of Volkow et al. Our findings agree with those of Volkow et al. (1991) in that our substance abuse group, tested more than 14 days after the last self-administration of cocaine, did not show higher absolute global glucose metabolism or higher rCMRglc in orbitofrontal cortex or in basal ganglia as reported for subjects withdrawn less than 1 week.

Data from a previous study in our laboratory (London et al. 1990a) were reanalyzed utilizing only the placebo data for those polysubstance abuse subjects that received placebo for their first PET session. The period of data collection for the two studies overlapped, but the present study was completed 3 years after the previous one. Nevertheless, the subjects were drawn from the same community using similar recruitment procedures, except that subjects in the earlier study were required to have experience with intravenous opiate use. Those subjects $(n=4)$ showed a pattern similar to the substance abuse group in the present study, with a large difference between frontal and occipital composite scores (frontal: $10.05 \pm 0.33$, occipital: $8.92 \pm 0.26$ ). On the other hand, preliminary data from a nonsubstance abuse group $(n=2)$ of a study in progress (Stapleton 
Table 4. Absolute Regional Cerebral Metabolic Rates for Glucose ${ }^{a}$

\begin{tabular}{|c|c|c|c|c|c|c|}
\hline \multirow[b]{2}{*}{ Neocortex } & \multicolumn{3}{|c|}{ Control } & \multicolumn{3}{|c|}{ Substance Abuse } \\
\hline & Left & Midline & Right & Left & Midline & Right \\
\hline \multicolumn{7}{|l|}{ Frontal lobe } \\
\hline Superior frontal gyrus ${ }^{b}$ & $8.25 \pm 0.27$ & & $8.45 \pm 0.24$ & $8.21 \pm 0.27$ & & $8.65 \pm 0.26$ \\
\hline Middle frontal & $9.70 \pm 0.42$ & & $10.63 \pm 0.35$ & $9.69 \pm 0.34$ & & $9.70 \pm 0.34$ \\
\hline \multicolumn{7}{|l|}{ Gyrus $^{b, c}$} \\
\hline Inferior frontal gyrus & $10.35 \pm 0.35$ & & $10.31 \pm 0.39$ & $10.09 \pm 0.28$ & & $9.79 \pm 0.36$ \\
\hline Precentral gyrus ${ }^{b, c}$ & $10.96 \pm 0.36$ & & $11.26 \pm 0.39$ & $10.15 \pm 0.43$ & & $11.06 \pm 0.42$ \\
\hline Gyrus rectus & & $8.72 \pm 0.45$ & & & $8.72 \pm 0.32$ & \\
\hline $\begin{array}{l}\text { Orbitofrontal cortex } \\
\text { Anterior cingulate gyrus }\end{array}$ & $8.12 \pm 0.39$ & $10.31 \pm 0.33$ & $8.28 \pm 0.29$ & $8.75 \pm 0.24$ & $10.37 \pm 0.33$ & $8.90 \pm 0.37$ \\
\hline \multicolumn{7}{|l|}{ Temporal lobe } \\
\hline Temporal pole & $6.23 \pm 0.26$ & & $6.16 \pm 0.28$ & $5.99 \pm 0.27$ & & $6.01 \pm 0.23$ \\
\hline Superior temporal & $6.71 \pm 0.21$ & & $6.32 \pm 0.27$ & $7.12 \pm 0.30$ & & $6.87 \pm 0.38$ \\
\hline \multicolumn{7}{|l|}{ Gyrus $^{b}$} \\
\hline Middle temporal gyrus & $8.09 \pm 0.35$ & & $8.33 \pm 0.38$ & $8.27 \pm 0.33$ & & $8.44 \pm 0.35$ \\
\hline Inferior temporal gyrus & $8.84 \pm 0.39$ & & $8.45 \pm 0.30$ & $8.41 \pm 0.37$ & & $8.45 \pm 0.31$ \\
\hline Insula & $10.41 \pm 0.46$ & & $10.13 \pm 0.49$ & $10.22 \pm 0.33$ & & $10.77 \pm 0.41$ \\
\hline \multicolumn{7}{|l|}{ Parietal lobe } \\
\hline Supramarginal gyrus ${ }^{b}$ & $8.72 \pm 0.32$ & & $9.61 \pm 0.33$ & $8.33 \pm 0.17$ & & $8.79 \pm 0.33$ \\
\hline Superior parietal gyrus & $9.84 \pm 0.35$ & & $9.88 \pm 0.36$ & $9.52 \pm 0.44$ & & $9.11 \pm 0.36$ \\
\hline Postcentral gyrus & $9.62 \pm 0.40$ & & $9.61 \pm 0.38$ & $8.80 \pm 0.37$ & & $8.96 \pm 0.35$ \\
\hline Paracentral lobule & & $9.32 \pm 0.47$ & & & $8.43 \pm 0.27$ & \\
\hline \multicolumn{7}{|l|}{ Occipital lobe } \\
\hline Primary visual cortex ${ }^{b}$ & $9.80 \pm 0.32$ & & $10.67 \pm 0.34$ & $9.15 \pm 0.32$ & & $9.76 \pm 0.36$ \\
\hline Lateral occipital gyrus $^{d}$ & $8.65 \pm 0.45$ & & $8.99 \pm 0.37$ & $7.61 \pm 0.22$ & & $8.16 \pm 0.39$ \\
\hline Cuneus $^{b}$ & $8.74 \pm 0.31$ & & $9.30 \pm 0.45$ & $8.04 \pm 0.47$ & & $8.45 \pm 0.42$ \\
\hline Precuneus & & $11.61 \pm 0.35$ & & & $11.53 \pm 0.47$ & \\
\hline \multicolumn{7}{|l|}{$\begin{array}{l}\text { Hippocampal formation } \\
\text { and amygdala }\end{array}$} \\
\hline Amygdala & $5.71 \pm 0.17$ & & $5.53 \pm 0.22$ & $5.49 \pm 0.17$ & & $5.04 \pm 0.15$ \\
\hline Hippocampus ${ }^{b}$ & $6.03 \pm 0.18$ & & $5.89 \pm 0.22$ & $6.06 \pm 0.14$ & & $5.65 \pm 0.20$ \\
\hline Parahippocampal gyrus & $7.34 \pm 0.32$ & & $7.47 \pm 0.29$ & $6.90 \pm 0.36$ & & $6.78 \pm 0.37$ \\
\hline \multicolumn{7}{|l|}{ Basal ganglia } \\
\hline Caudate nucleus & $9.13 \pm 0.39$ & & $9.12 \pm 0.51$ & $8.62 \pm 0.28$ & & $8.62 \pm 0.18$ \\
\hline Putamen $^{b}$ & $9.86 \pm 0.54$ & & $10.28 \pm 0.54$ & $9.47 \pm 0.28$ & & $10.09 \pm 0.33$ \\
\hline \multicolumn{7}{|l|}{ Thalamus } \\
\hline Lateral $^{b}$ & $7.80 \pm 0.38$ & & $8.29 \pm 0.34$ & $7.49 \pm 0.26$ & & $7.77 \pm 0.29$ \\
\hline Medial & & $7.23 \pm 0.30$ & & & $7.60 \pm 0.25$ & \\
\hline Midbrain & & $5.59 \pm 0.28$ & & & $5.18 \pm 0.25$ & \\
\hline Pons & & $5.35 \pm 0.29$ & & & $5.44 \pm 0.24$ & \\
\hline \multicolumn{7}{|l|}{ Cerebellum } \\
\hline Cortex & $8.37 \pm 0.29$ & & $8.44 \pm 0.35$ & $8.05 \pm 0.28$ & & $8.01 \pm 0.28$ \\
\hline Vermis & & $7.04 \pm 0.28$ & & & $6.90 \pm 0.23$ & \\
\hline
\end{tabular}

${ }^{a}$ Each value is the mean $\pm \mathrm{SEM}$ regional cerebral metabolic rate for glucose (rCMRglc, $\mathrm{mg} / 100 \mathrm{~g} / \mathrm{min}$ ). Values of $\mathrm{rCMRglc}$ are not adjusted for global metabolism.

${ }^{b}$ Laterality factor, Left different from Right, $p<.05$.

${ }^{c}$ Interaction of Group by Laterality factors, $p<.05$.

${ }^{d}$ Group factor, Substance Abuse different from Control, $p<.05$.

et al. 1992) showed a pattern like that of the control group in this study, with no difference between frontal and occipital composite scores (frontal: $9.98 \pm 0.29$, occipital: $9.96 \pm 0.24$ ). Thus the data from other studies in our laboratory using similar procedures are consistent with the present study.

Comparing the present data to the most similar study of other investigators (Volkow et al. 1992b), it is clear that in both studies there was a tendency for absolute rCMRglc to be lower in substance abuse than in control groups, but Volkow et al. (1992b) found the largest differences in frontal lobe structures, and in our study the difference was largest in occipital lobe structures. Among the factors that may contribute to these topographic discrepancies are differences in the drug histories of the subjects (cocaine vs. polydrug abuse), differences in the experimental conditions (eyes closed vs. eyes open), and differences in ROI measurement.

Another methodological issue may be relevant to these findings. Both substance abuse and control sub- 
Table 5. Regional Cerebral Metabolic Rates for Glucose, Adjusted for Global Metabolism ${ }^{a}$

\begin{tabular}{|c|c|c|c|c|c|c|}
\hline \multirow[b]{2}{*}{ Neocortex } & \multicolumn{3}{|c|}{ Control } & \multicolumn{3}{|c|}{ Substance Abuse } \\
\hline & Left & Midline & Right & Left & Midline & Right \\
\hline \multicolumn{7}{|l|}{ Frontal lobe } \\
\hline Superior frontal gyrus ${ }^{b, c}$ & 8.05 & & 8.26 & 8.43 & & 8.86 \\
\hline Middle frontal gyrus ${ }^{c, d}$ & 9.47 & & 10.40 & 9.94 & & 9.95 \\
\hline Inferior frontal gyrus & 10.10 & & 10.07 & 10.33 & & 10.04 \\
\hline Precentral gyrus ${ }^{c, d}$ & \multirow{2}{*}{\multicolumn{3}{|c|}{8.47}} & \multirow{2}{*}{\multicolumn{3}{|c|}{9.00}} \\
\hline Gyrus rectus & & & & & & \\
\hline Orbitofrontal cortex ${ }^{b}$ & \multirow[t]{2}{*}{7.92} & & 8.08 & \multirow[t]{2}{*}{8.97} & & \multirow[t]{2}{*}{9.12} \\
\hline Anterior cingulate gyrus & & 10.06 & & & 10.63 & \\
\hline \multicolumn{7}{|l|}{ Temporal lobe } \\
\hline Temporal pole & 6.07 & & 6.00 & 6.17 & & 6.18 \\
\hline Superior temporal gyrus ${ }^{b, c}$ & 6.59 & & 6.19 & 7.26 & & 7.01 \\
\hline Middle temporal gyrus ${ }^{b}$ & 7.84 & & 8.09 & 8.54 & & 8.71 \\
\hline Inferior temporal gyrus & 8.61 & & 8.23 & 8.66 & & 8.70 \\
\hline Insula $b^{b, d}$ & 10.09 & & 9.81 & 10.53 & & 11.09 \\
\hline \multicolumn{7}{|l|}{ Parietal lobe } \\
\hline Supramarginal gyrus ${ }^{c}$ & 8.52 & & 9.41 & 8.54 & & 9.00 \\
\hline Superior parietal gyrus & 9.56 & & 9.60 & 9.80 & & 9.39 \\
\hline Postcentral gyrus & 9.35 & & 9.34 & 9.11 & & 9.26 \\
\hline Paracentral lobule & \multicolumn{3}{|c|}{9.11} & \multicolumn{3}{|c|}{8.66} \\
\hline \multicolumn{7}{|l|}{ Occipital lobe } \\
\hline Primary visual cortex ${ }^{c}$ & 9.62 & & 10.50 & 9.32 & & 9.94 \\
\hline Lateral occipital gyrus & 8.40 & & 8.75 & 7.85 & & 8.40 \\
\hline Cuneus $^{c}$ & 8.45 & & 9.01 & 8.33 & & 8.74 \\
\hline Precuneus & \multicolumn{3}{|c|}{11.29} & \multicolumn{3}{|c|}{11.85} \\
\hline \multicolumn{7}{|l|}{$\begin{array}{l}\text { Hippocamal formation } \\
\text { and amygdala }\end{array}$} \\
\hline Amygdala ${ }^{c}$ & 5.61 & & 5.42 & 5.61 & & 5.17 \\
\hline Hippocampus ${ }^{c}$ & 5.93 & & 5.79 & 6.17 & & 5.75 \\
\hline Parahippocampal gyrus & 7.15 & & 7.29 & 7.11 & & 6.99 \\
\hline \multicolumn{7}{|l|}{ Basal ganglia } \\
\hline Caudate nucleus & 8.87 & & 8.87 & 8.88 & & 8.88 \\
\hline Putamen ${ }^{c}$ & 9.57 & & 9.99 & 9.76 & & 10.38 \\
\hline \multicolumn{7}{|l|}{ Thalamus } \\
\hline Lateral $^{c}$ & 7.58 & & 8.07 & 7.71 & & 7.99 \\
\hline Medial & & 7.08 & & \multirow{3}{*}{\multicolumn{3}{|c|}{$\begin{array}{l}7.74 \\
5.41 \\
5.63\end{array}$}} \\
\hline Midbrain & & 5.38 & & & & \\
\hline Pons & & 5.17 & & & & \\
\hline \multicolumn{7}{|l|}{ Cerebellum } \\
\hline Cortex & 8.17 & & 8.24 & 8.27 & & 8.23 \\
\hline Vermis & & 6.89 & & & 7.07 & \\
\hline
\end{tabular}

${ }^{a}$ Each value is the mean regional cerebral metabolic rate for glucose (rCMRglc, $\mathrm{mg} / 100 \mathrm{~g} / \mathrm{min}$ ).

${ }^{b}$ Group factor. Substance Abuse different from Control, $p<.05$.

${ }^{c}$ Laterality factor, Left different from Right, $p<.05$.

${ }^{d}$ Interaction of Group by Laterality factors, $p<.05$.

jects received a placebo injection, but they would be expected to respond differently to this event. The substance abuse subjects may have shown conditioned drug effects, even though the PET study situation was markedly different from the typical conditions of drug self-administration. Since the substance abuse subjects were studied in a double-blind procedure, they may have experienced an emotional reaction (e.g., disappointment) when they realized that the injection was placebo. Such a reaction did not occur for the control subjects, who had no intravenous drug experience and expected to receive placebo.
The tendency for the substance abuse group to show overall lower absolute rCMRglc than the control group was more pronounced in posterior structures. When the data were analyzed using global metabolic rate as a covariate, relative rCMRglc was revealed to be higher in the substance abuse group than in the control group in frontal and temporal areas. Absolute and relative measures of rCMRglc may yield different information. In this study, since the control group showed a tendency toward higher global metabolic rates, and the metabolic rates for most ROIs showed high positive correlations with global metabolic rate, normaliz- 
ing the data by ANCOVA tended to dampen differences due to control values being greater than those in the substance abuse group and to enhance differences in the opposite direction. It may be noteworthy that the group difference in normalized glucose metabolism, with higher levels in the substance abuse group, was largest in orbitofrontal cortex, a limbic structure that has been implicated in emotional control, including aggressive and impulsive behaviors. In this regard, previous studies have identified abnormalities in orbitofrontal metabolism in patients with obsessive compulsive disorder (Baxter 1990; Benkelfat et al. 1990). Frontal normalized rCMRglc also is abnormal in patients with borderline personality disorder (Goyer et al. 1994); however, as none of the subjects in either group met diagnostic criteria for borderline personality disorder, this disorder was unrelated to the higher normalized rCMRglc in the substance abuse group.

Psychometric assessment of the subjects in this study (including also the substance abuse subjects who received placebo for the second PET) indicated that the substance abuse group showed significantly higher scores for impulsivity on the Eysenck ImpulsivenessVenturesomeness-Empathy scale, and for aggressiveness on the Buss-Durkee Hostility Inventory than the control group (Parsons et al. 1987; Stapleton et al. 1991a, b). The substance abuse group also showed higher scores than the control group on the Psychopathic Deviate scale (4) of the Minnesota Multiphasic Personality Inventory and a higher incidence of Antisocial Personality Disorder. Therefore, differences in rCMRglc between the groups could be related to psychological characteristics associated with substance abuse.

It should be pointed out that these psychological characteristics, as well as patterns of glucose metabolism discussed in this study, may be specific to a certain type of substance abuse subject. Our subjects were drawn from a population of adult males who were not seeking treatment for their substance abuse problem. It remains to be seen whether conclusions concerning cerebral and psychological function in this population would also hold true for different substance abuse populations, such as women or patients in substance abuse treatment programs.

\section{ACKNOWLEDGMENTS}

The authors thank W. Robert Lange, M.D., and Carlo Contoreggi, M.D., for medical coverage and Merrily Smith, R.N., and Robin Stauffer, R.N., for nursing services. Our appreciation is extended to Valerie O'Brien, Jennifer Schmidt, and Loretta Spurgeon for assistance in data collection and analysis. We thank David Clough, C.N.M.T., for operation of the PET scanner and Stephen F. Gilson, Ph.D., for helpful discussions. The NIDA Intramural PET Research Program is supported by the Counterdrug Technology Assessment Center, Office of National Drug Control Policy, Office of the President.

\section{REFERENCES}

Allison WM, Jerrom DWA (1984): Glue sniffing: A pilot study of the cognitive effects of long-term use. Int J Addict 19:453-458

American Psychiatric Association, Committee on Nomenclature and Statistics (1980): Diagnostic and Statistical Manual of Mental Disorders, ed 3. Washington, DC, American Psychiatric Association

Baxter LR (1990): Brain imaging as a tool in establishing a theory of brain pathology in obsessive compulsive disorder. J Clin Psychiatry 51:22-25

Benkelfat C, Nordahl TE, Semple WE, King C, Murphy DL, Cohen RM (1990): Local cerebral glucose metabolic rates in obsessive-compulsive disorder: Patients treated with clomipramine. Arch Gen Psychiatry 47:840-848

Berglund M, Ingvar DH (1976): Cerebral blood flow and its regional distribution in alcoholism and in Korsakoff's psychosis. J Stud Alcohol 37:586-597

Cascella NG, Pearlson G, Wong DF, Broussolle E, Nagoshi C, Margolin RA, London ED (1991): Effects of substance abuse on ventricular and sulcal measures assessed by computerised tomography. Br J Psychiatry 159:217-221

Dixon WJ, Brown MB, Engelman L, Hill MA, Jennrich RI (1988): BMDP Statistical Software Manual. Berkeley, University of California Press

Eckardt MJ, Ryback RS (1981): Neuropsychological concomitants of alcoholism. In Galanter M (ed), Currents in Alcoholism: Recent Advances in Research and Treatment, New York, Grune \& Stratton, pp 5-27

Fauman MA, Fauman BJ (1978): The psychiatric aspects of chronic phencyclidine use: A study of chronic PCP users. In Petersen RC, Stillman RC (eds), Phencyclidine (PCP) Abuse: An Appraisal, Rockville, MD, NIDA Research Monograph, pp 183-200

Goyer PF, Andreason PJ, Semple WE, Clayton AH, King AC, Compton-Toh BA, Schulz SC, Cohen RM (1994): Positron-emission tomography and personality disorders. Neuropsychopharmacology 10:21-28

Grant I, Mohns L (1975): Chronic cerebral effects of alcohol and drug abuse. Int J Addict 10:883-920

Grant I, Adams KM, Carlin AS, Rennick PM, Judd LL, Schooff K (1978): The collaborative neuropsychological study of polydrug users. Arch Gen Psychiatry 35:1063-1074

Haertzen CA (1974): An Overview of Addiction Research Center Inventory Scales (ARCI): An Appendix and Manual of Scales. Rockville, MD, Dept. Health Education and Welfare Publication No. (ADM) 74-92, NIDA

Hanaway J, Scott WR, Strother CM (1980): Atlas of the Human Brain and the Orbit for Computed Tomography. St Louis, Warren H. Green

Holman BL, Carvalho PA, Mendelson J, Teoh SK, Nardin R, Hallgring E, Hebben N, Johnson KA (1991): Brain perfusion is abnormal in cocaine-dependent polydrug users: A study using technetium-99m-HMPAO and ASPECT. J Nucl Med 32:1206-1210

Huang S-C, Phelps ME, Hoffman EJ, Sideris K, Selin CJ, Kuhl DE (1980): Noninvasive determination of local cerebral metabolic rate of glucose in man. Am J Physiol 238: E69-E82 
Knox JW, Nelson JR (1966): Permanent encephalopathy from toluene inhalation. N Engl J Med 275:1494-1496

Kushner MJ, Rosenquist A, Alavi A, Rosen M, Dann R, Fazekas F, Bosley T, Greenberg J, Reivich M (1988): Cerebral metabolism and patterned visual stimulation: A positron emission tomographic study of the human visual cortex. Neurology 38:89-95

Lewis JE, Hordan RB (1986): Neuropsychological assessment of phencyclidine abusers. NIDA Res Monogr 64:190-208

Lipton RB, Choy-Kwong M, Solomon S (1989): Headaches in hospitalized cocaine users. Headache 29:225-228

London ED, Broussolle EPM, Links JM, Wong DF, Cascella NG, Dannals RF, Sano M, Herning R, Snyder FR, Rippetoe LR, Toung TJK, Jaffe JH, Wagner HN Jr (1990a): Morphine-induced metabolic changes in human brain: Studies with positron emission tomography and [fluorine 18]fluorodeoxyglucose. Arch Gen Psychiatry 47: 73-81

London ED, Cascella NG, Wong DF, Phillips RL, Dannals RF, Links JM, Herning R, Grayson R, Jaffe JH, Wagner HN Jr (1990b): Cocaine-induced reduction of glucose utilization in human brain. A study using positron emission tomography and [fluorine 18] fluorodeoxyglucose. Arch Gen Psychiatry 47:567-574

Mahmood Z (1983): Cognitive functioning of solvent abusers. Scott Med J 28:276-280

Martin PR, Rio D, Adinoff B, Johnson JL, Bisserbe J-C, Rawlings RR, Rohrbaugh JW, Stapleton JM, Eckardt MJ (1992): Regional cerebral glucose utilization in chronic organic mental disorders associated with alcoholism. J Neuropsychiatry Clin Neurosci 4:159-167

McLellan AT, Luborsky L, Woody GE, O'Brien CP (1980): An improved evaluation instrument for substance abuse patients: The Addiction Severity Index. J Nerv Ment Dis 168:26-33

Meek PS, Clark HW, Solana VL (1989): Neurocognitive impairment: The unrecognized component of dual diagnosis in substance abuse treatment. J Psychoactive Drugs 21:153-160

Miller L (1985): Neuropsychological assessment of substance abusers: Review and recommendations. J Subst Abuse Treat 2:5-17

Muntaner C, Kumor KM, Nagoshi C, Jaffe JH (1989): Intravenous cocaine infusions in humans: Dose responsivity and correlations of cardiovascular vs. subjective effects. Pharmacol Biochem Behav 34:697-703

Nalls G, Disher A, Daryabagi J, Zant Z, Eisenman J (1989): Subcortical cerebral hemorrhages associated with cocaine abuse: CT and MR findings. J Comput Assist Tomogr 13:1-5

Parsons OA, Farr SP (1981): The neuropsychology of alcohol and drug use. In Filskov SB, Boll TJ (eds), Handbook of Clinical Neuropsychology. New York, Wiley, pp 320-365

Parsons OA, Butters, N. Nathan PE (1987): Neuropsychology of Alcoholism: Implications for Diagnosis and Treatment, New York, The Guilford Press

Phelps ME, Mazziotta JC, Kuhl DE, Nuwer M, Packwood J, Metter J, Engel J Jr (1981): Tomographic mapping of human cerebral metabolism: Visual stimulation and deprivation. Neurology 31:517-529
Porjesz B, Begleiter H (1983): Brain dysfunction and alcohol. In Kissin B, Begleiter H (eds), The Biology of Alcoholism. Vol. 7, The Pathogenesis of Alcoholism Biological Factors. New York, Plenum, pp 415-483

Robins LN, Helzer JE, Croughan J, Ratcliff KS (1981): National Institute of Mental Health Diagnostic Interview Schedule: Its history, characteristics, and validity. Arch Gen Psychiatry 38:381-389

Rosenberg NL, Spitz MC, Filley CM, Davis KA, Schaumburg $\mathrm{HH}$ (1988): Central nervous system effects of chronic toluene abuse-Clinical, brainstem evoked response and magnetic resonance imaging studies. Neurotoxicol Teratol 10:489-495

Rowbotham MC (1988): Neurologic aspects of cocaine abuse [medical staff conference]. West J Med 149:442-448

Sachs H, Russell JAG, Christman DR, Cook B (1987): Alteration of regional cerebral glucose metabolic rate in nonKorsakoff chronic alcoholism. Arch Neurol 44:1242-1251

Satel SL, Gawin FH (1989): Migrainelike headache and cocaine use. JAMA 261:2995-2996

Schmitt R, Capo T, Frazier H, Boren D (1984): Cranial electrotherapy stimulation treatment of cognitive brain dysfunction in chemical dependence. J Clin Psychiatry 45:60-63

Snyder FR, Davis FC, Henningfield JE (1989): The tobacco withdrawal syndrome: Performance decrements assessed on a computerized test battery. Drug Alcohol Depend 23:259-266

Spivey WH, Euerle B (1990): Neurologic complications of cocaine abuse. Ann Emerg Med 19:1422-1428

Stapleton JM, Spurgeon ML, Morgan MJ, Yung BCK, Phillips RL, Cascella NG, Jaffe JH, Wong DF, London ED (1991a): Psychological characteristics and cerebral glucose metabolism in substance abusers and control subjects. Presented at the 30th Annual Meeting of the American College of Neuropsychopharmacology, December 9-13, San Juan, PR

Stapleton JM, Yung BCK, Spurgeon ML, Morgan MJ, Phillips RL, Cascella NG, Jaffe JH, Wong DF, London ED (1991b): Brain metabolism and psychological parameters in substance abusers. J Cereb Blood Flow Metab S11:391

Stapleton JM, Henningfield JE, Wong DF, Phillips RL, Gilson SF, Grayson RF, Dannals RF, London ED (1992): Effects of nicotine on cerebral metabolism and subjective responses in human volunteers. Soc Neurosci Abstr 18:1074

Volkow ND, Mullani N, Gould KL, Adler S, Krajewski K (1988): Cerebral blood flow in chronic cocaine users: A study with positron emission tomography. Br J Psychiatry 152:641-648

Volkow ND, Fowler JS, Wolf AP, Hitzemann R, Dewey S, Bendriem B, Alpert R, Hoff A (1991): Changes in brain glucose metabolism in cocaine dependence and withdrawal. Am J Psychiatry 148:621-626

Volkow ND, Hitzemann R, Wang G-J, Fowler JS, Burr G, Pascani K, Dewey SL, Wolf AP (1992a): Decreased brain metabolism in neurologically intact healthy alcoholics. Am J Psychiatry 149:1016-1022

Volkow ND, Hitzemann R, Wang G-J, Fowler JS, Wolf AP, Dewey SL, Handlesman L (1992b): Long-term frontal 
brain metabolic changes in cocaine abusers. Synapse 11:184-190

Wu JC, Buchsbaum MS, Johnson C, Bunney WE (1991): Positron emission tomography study of phencyclidine users as a possible drug model of schizophrenia. In
Nakazawa T (ed), Biological Basis of Schizophrenic Disorders, Basel, Karger, pp 217-220

Zachary RA (1986): Shipley Institute of Living Scale, ed 4. Los Angeles, Western Psychological Services

Zuckerman M (1986): Sensation seeking and the endogenous deficit theory of drug abuse. NIDA Res Monogr 74:59-70 